\title{
TRANSPORTE PÚBLICO COLETIVO POR ÔNIBUS EM BELO HORIZONTE: RELACIONANDO A ACESSIBILIDADE POTENCIAL À MOBILIDADE EFETIVA A PARTIR DO MODELO GWR
}

\author{
Daniela Antunes Lessa
}

\section{Resumo}

Os conceitos de acessibilidade e mobilidade têm sido amplamente utilizados na literatura, sob as mais diversas abordagens e aplicações. A acessibilidade está relacionada com a potencialidade de chegar aos destinos. Essa potencialidade, disponibilizada pelo sistema de transporte e pelo uso do solo, pode permitir que diferentes tipos de pessoas desenvolvam suas atividades. A mobilidade está associada à habilidade de um indivíduo se deslocar. Porém, os termos, quando não considerados sinônimos, são motivo de equívocos e imprecisões. Parte dessa confusão pode ser resultante da relação entre os conceitos. A mobilidade, facilidade de deslocamento, está relacionada com impedância (dificuldade de se chegar a um destino), componente da acessibilidade. Sendo a acessibilidade e a mobilidade condições fundamentais para a vida urbana, este trabalho tem como objetivo principal verificar em que medida a acessibilidade potencial, tratada neste trabalho como a facilidade de acesso ao transporte público por ônibus, interfere na mobilidade efetiva da população do município de Belo Horizonte. Para tanto, foram desenvolvidos três indicadores de acessibilidade potencial e três indicadores de mobilidade efetiva, que resultaram, respectivamente, em um Índice de Acessibilidade Potencial (IAP) e um Índice de Mobilidade Efetiva (IME). A análise espacial, realizada a partir do modelo Geographically Weighted Regression (GWR), verifica que o potencial de utilização de modo de transporte não permite, necessariamente, que destinos desejados possam ser atingidos por aqueles modos, uma vez que a mobilidade também pode estar associada a outra(s) variável(is). Os resultados obtidos possibilitam o reconhecimento de padrões de demanda por transporte público por ônibus e deslocamento da população, distribuídos em nível local, e podem subsidiar, em trabalhos futuros, a formulação de medidas que visem à adequação da oferta de transporte público, de forma a estabelecer condições para que seja adequadamente inserido com prioridade nos deslocamentos urbanos, gerando benefícios para a mobilidade e acessibilidade urbana e metropolitana.

Palavras-chave: Acessibilidade; Mobilidade; Regressão Geograficamente Ponderada; Sistema de Informação Geográfica. 


\section{INTRODUÇÃO}

O sistema de transporte tem como objetivo garantir a mobilidade, o acesso e a integração dos indivíduos às diferentes atividades, que são definidas e condicionadas pelo uso e ocupação do solo (CAMPOS e RAMOS, 2005). Além disso, ele influencia os custos de produção, os fluxos de comércio, o bem estar social e a determinação de áreas de mercado para as regiões, tendo, assim, um papel importante no crescimento e desenvolvimento econômico das cidades (DINIZ, 1987; RIGOLON e PICCININI, 1997; ALMEIDA, 2004; BARROS e RAPOSO; 2002; AGUILAR et al., 2010). O intenso e descontrolado crescimento das cidades e suas consequências têm sido foco de vários estudos e análises, bem como determinações legais, com o objetivo de buscar melhores condutas para o planejamento e gestão de cidades (GONZAGA e KNEIB, 2016).

Nas cidades brasileiras; é possível identificar problemas urbanos relacionados ao crescimento desordenado e à gestão ineficiente e desarticulada. Muitos desses transtornos atualmente observados derivam ou têm alguma relação com os sistemas de transporte e circulação. Questões como inadequação da oferta de transporte coletivo; congestionamentos; poluição sonora; poluição do ar e acidentes e falta de acesso à cidade, têm levado a um entendimento generalizado de que a maioria das cidades deve rever suas estratégias, a fim de promover padrões satisfatórios de mobilidade e acessibilidade (OLIVEIRA e RODRIGUES DA SILVA, 2015; GONZAGA e KNEIB, 2016). Recentemente foi instituída a Política Nacional de Mobilidade Urbana, conhecida como "Lei de Mobilidade", aprovada em janeiro de 2012, que tem por objetivo:

\footnotetext{
[...] contribuir para o acesso universal à cidade, o fomento e a concretização das condições que contribuam para a efetivação dos princípios, objetivos e diretrizes da política de desenvolvimento urbano, por meio do planejamento e da gestão democrática do Sistema Nacional de Mobilidade Urbana (BRASIL, 2012, p. 1).
}

Raia Jr. (2000, p. 187) afirma que "os conceitos de acessibilidade e mobilidade têm sido amplamente utilizados na literatura, sob as mais diversas abordagens e aplicações". Embora alguns autores tenham manifestado a importância das definições e da complementaridade dos dois conceitos, poucos foram o que os associaram de forma a verificar a real influência de um sobre o outro (RAIA JR., 2000).

Sendo a acessibilidade e a mobilidade condições fundamentais para a organização social e a vida urbana (VERAS et al., 2016), este trabalho investiga a relação entre esses dois conceitos. Cadernos do Leste Artigos Científicos Belo Horizonte, Jan.-Dez. Vol.16, n¹6, 2016 
Para tanto, procurou-se mensurar indicadores e construir índices que apontam características dessa relação, tendo como foco os deslocamentos por transporte público por ônibus. Cabe ressaltar que a avaliação da acessibilidade e da mobilidade por transporte público coletivo possibilita contribuir com políticas públicas que incentivem esse modo, de forma a estabelecer condições para que seja adequadamente inserido com prioridade nos deslocamentos urbanos, podendo, desse modo, gerar benefícios para a mobilidade e acessibilidade urbana e metropolitana (GONZAGA e KNEIB, 2016).

O objetivo do trabalho é construir índices, nomeados Índice de Acessibilidade Potencial e Índice de Mobilidade Efetiva, e relacioná-los, de forma a verificar em que medida a acessibilidade potencial, tratada neste trabalho como a facilidade de acesso ao transporte público por ônibus, interfere na mobilidade efetiva da população do município de Belo Horizonte. De forma prática, buscou-se analisar a interferência do acesso ao transporte público por ônibus na facilidade do deslocamento diário das pessoas, com base em indicadores e índices, a partir de um modelo de regressão geograficamente ponderada.

O presente trabalho é constituído por cinco seções. Na Seção 1, representado por esta Introdução, apresenta-se o contexto em que se insere o problema proposto e sua justificativa, seus objetivos e a delimitação da área de estudo. Na Seção 2 tem-se o referencial teórico com o objetivo de apresentar as definições e os trabalhos relacionados à mobilidade e à acessibilidade urbanas, conceitos fundamentais para o entendimento do estudo. $\mathrm{Na}$ Seção 3, a metodologia de pesquisa foi detalhada. Na Seção 4, os resultados obtidos com a regressão geograficamente ponderada, foram apresentados, analisados e discutidos. Finalmente, na Seção 5 foram expostas as considerações finais do projeto.

\section{2- ACESSIBILIDADE E MOBILIDADE}

O conceito de acessibilidade tem sido amplamente utilizado em diferentes vertentes do conhecimento desde o século passado, sendo, dessa forma, alvo de discussões, controvérsias e desencontros (KOENIG, 1980; MAKRI e FOLKESSON, 1999; RAIA JR., 2000 e CARDOSO, 2007; LOBO et al., 2010). O vasto emprego do termo conduz a equívocos conceituais, que podem levar à sua descaracterização. Não raro, os termos acessibilidade e mobilidade, quando não considerados sinônimos, são motivo de equívocos e imprecisões (RAIA JR., 2000; ULYSSÉA 
NETO e SILVA, 2004; CARDOSO, 2007; LOBO et al., 2013). Ulysséa Neto e Silva (2004, p. 774) apontam:

\begin{abstract}
$\mathrm{Na}$ literatura pode-se muitas vezes encontrar uma certa confusão no que tange à conceituação, e respectivas medidas, de acessibilidade e de mobilidade, principalmente quando estas medidas relacionam-se apenas à questão da facilidade ou impedância nos deslocamentos. Nesta situação interpreta-se a acessibilidade como um atributo dependente unicamente do sistema de transporte sem considerar o grau de atração das oportunidades oferecidas nas potenciais zonas de destino, ficando mesclados os conceitos de mobilidade e acessibilidade.
\end{abstract}

Hansen (1959), Jones (1981), Tagore e Sikdar (1995), Vasconcellos (2001) e Lima et al. (2016) fornecem definições que auxiliam na diferenciação dos termos, relacionando a acessibilidade com a oportunidade que um indivíduo possui para realizar uma atividade particular ou uma série de atividades em um dado local. Assim, o termo refere-se não apenas à facilidade de cruzar espaço, mas à potencialidade de chegar aos destinos. Essa potencialidade, disponibilizada pelo sistema de transporte e pelo uso do solo, pode permitir que diferentes tipos de pessoas desenvolvam suas atividades. A mobilidade, porém, está associada à habilidade de um indivíduo se deslocar, em virtude de dois componentes: 1) desempenho do sistema de transporte, por sua capacidade de interligar locais distintos; e 2) características próprias do indivíduo, relacionadas às suas condições física e econômica, ao seu grau de inserção perante o sistema de transporte, e às suas necessidades (JONES, 1981; TAGORE e SIKDAR, 1995 e VASCONCELLOS, 2001).

De forma semelhante, Lobo et al. (2013, p. 517) afirmam que a mobilidade abriga estreitas relações com a acessibilidade visto que:

[...] envolve a combinação de políticas de uso e ocupação do solo, transporte e trânsito, uma vez que a geração de proximidades entre residência e postos de trabalho [...], somadas a uma boa inserção dos cidadãos perante os modos de transporte disponíveis [...] e a condições adequadas de circulação viária, possibilita [...]um melhor aproveitamento das oportunidades de "consumo" do espaço urbano.

Bigolini et al. (2009), na mesma linha de pensamento, descrevem a mobilidade como a resultante da conjugação da acessibilidade à necessidade, sendo então necessidade + acessibilidade $=$ mobilidade. Assim, a mobilidade e a acessibilidade, juntas, influenciam a capacidade do indivíduo de viajar (MORRIS et al., 1978). Noutros termos, acessibilidade associa-se à capacidade de alcançar um determinado lugar, sendo comumente mensurada pelo atributo tempo de viagem, enquanto 
que mobilidade, medida pelo número de viagens/dia por pessoa, relaciona-se com a facilidade com que o deslocamento pode ser realizado (SATHISAN E SRINIVASAN, 1998).

Parte da confusão no uso desses termos pode resultar da relação entre eles. A mobilidade, potencial de deslocamento, está relacionada com impedância (dificuldade de se chegar a um destino), componente da acessibilidade. Assim, as políticas para aumentar a mobilidade geralmente irão aumentar a acessibilidade (RAIA JR., 2000; HANDY, 2002). Porém, segundo Handy (2002), uma boa acessibilidade não é condição suficiente e nem necessária para uma boa mobilidade. A capacidade para utilizar um modo de transporte não permite, necessariamente, que destinos desejados possam ser atingidos por aqueles modos; e, de maneira recíproca, a conectividade aos destinos, facilitada por um determinado modo, não o torna, obrigatoriamente, acessível ao “viajante” potencial (RAIA JR., 2000).

\section{1- Notas sobre a mobilidade e a acessibilidade em Belo Horizonte}

O município de Belo Horizonte (MG), segundo os dados do Censo de 2010, tem uma população de aproximadamente 2,5 milhões de habitantes, distribuídos em área de cerca de 330 $\mathrm{km}^{2}$, portanto, com densidade populacional de cerca de $7.100 \mathrm{hab} / \mathrm{km}^{2}$ (BRASIL, 2010b). A exemplo do que ocorre em boa parte das capitais brasileiras, verifica-se a reprodução de precariedades na provisão de acessibilidade e mobilidade urbanas no município, o que contribui para o agravamento das situações de vulnerabilidade social e degradação ambiental.

A distribuição da acessibilidade e da mobilidade espaciais é caracterizada por iniquidades, resultantes da estruturação de um espaço de circulação no qual, os privilégios do transporte individual são mantidos e as parcelas mais vulneráveis (pedestres, ciclistas e usuários de transporte público coletivo) têm sido preteridos nos seus anseios relacionados à circulação intraurbana (LOBO et al., 2010; LOBO et al., 2012; CARDOSO e LOBO, 2013; LOBO et al., 2013). Nesse cenário, mesmo com os recentes esforços de mitigar as distorções no provimento de acessibilidade, notadamente a partir da implantação do sistema de BRT (Bus Rapid Transit) em alguns dos principais corredores viários da cidade (não incluindo a sua dimensão metropolitana), importantes parcelas da população têm procurado resolvê-las individualmente.

Em 2008, 54,5\% das viagens intramunicipais diárias eram realizadas por ônibus e 45,5\% feitas em automóveis. Segundo dados do Plano de Mobilidade Urbana de Belo Horizonte, a Cadernos do Leste

Artigos Científicos

Belo Horizonte, Jan.-Dez. Vol.16, n¹6, 2016 
ausência de novos investimentos na melhoria dos transportes públicos promoverá uma inversão neste quadro em 2020 , sendo $52 \%$ das viagens realizadas por automóveis e $48 \%$ pelo transporte coletivo (BELO HORIZONTE, 2010). Além disso, o avanço da motorização tem contribuído para a manutenção de baixas velocidades médias do transporte coletivo (modo ônibus) na capital mineira que, em 2008, era de $19,8 \mathrm{~km} / \mathrm{h}$ na rede viária municipal e $14,3 \mathrm{~km} / \mathrm{h}$ na área central nos horários de pico. Situação semelhante, resguardadas as devidas proporções, era vivenciada pelos usuários de automóveis, cujos veículos apresentavam velocidade média de $26,2 \mathrm{~km} / \mathrm{h}$ no sistema viário municipal e $18 \mathrm{~km} / \mathrm{h}$ no centro no mesmo período (BELO HORIZONTE, 2010).

A realidade do município é, essencialmente, a das sociedades urbanizadas subdesenvolvidas, onde ocorre um predomínio absoluto do ônibus como principal meio de transporte coletivo e de automóveis, servindo a uma minoria da população, mas moldando o perfil dos investimentos em infraestrutura de transportes e toda a lógica do desenvolvimento urbano (BRASIL, 2004). Segundo o relatório da Pesquisa Origem Destino 2012 (MINAS GERAIS, 2012), o censo demográfico (BRASIL, 2010b) e os relatórios estatísticos de frota (BRASIL 2000; 2010; 2016), enquanto a população de Belo Horizonte cresceu aproximadamente 6\%, entre 2000 e 2010 (de 2.238.526 para 2.375.151), a frota total de veículos cresceu 90\% (de 706.480 para 1.340 .071 ).

A taxa de motorização era de 0,56 veículos por habitante em 2010 e passou para $0,70 \mathrm{em}$ 2016, valor muito próximo da cidade de São Paulo, que apresentava, nos respectivos anos 0,57 e 0,64 veículos por habitante (BRASIL, 2010a; BRASIL, 2010b; BRASIL, 2016). Além disso, a taxa de motorização verificada no município é muito próxima a de países como Canadá (0,64), França $(0,66)$ e Japão $(0,70)$, segundo dados de 2013 da Organisation for Economic Cooperation and Development (OECD, 2013). Embora essa taxa seja próxima da média de países desenvolvidos, existem inúmeras variáveis que fazem o trânsito do município ser, muitas vezes, sentido de maneira mais intensa. Entre as causas, o planejamento urbano ineficaz, o uso exagerado do veículo particular, além das más condições do transporte público. Assim o crescimento da motorização experimentado pelo município, não veio acompanhado de avanços no bem-estar urbano (BRASIL, 2015). Apesar de a taxa de motorização ser um indicador geral de crescimento econômico de cidades e países, tal análise contrapõe-se aos preceitos básicos da mobilidade urbana sustentável:

Cadernos do Leste

[...] conjunto de políticas de transporte e circulação que visa proporcionar o acesso amplo e democrático ao espaço urbano, através da priorização dos modos não-motorizados e

Artigos Científicos

Belo Horizonte, Jan.-Dez. Vol.16, n¹6, 2016 
coletivos de transporte, de forma efetiva, que não gere segregações espaciais, socialmente inclusiva e ecologicamente sustentável. ou seja: baseado nas pessoas e não nos veículos (BRASIL, 2004, p. 13).

A análise das condições de mobilidade e acessibilidade espaciais em Belo Horizonte, através de indicadores específicos, como proposto neste trabalho, permite a construção de um diagnóstico que supera o simples (re)conhecimento de uma condição dada. Os resultados obtidos, com base no confronto de índices de acessibilidade potencial e de mobilidade efetiva, permitem o reconhecimento de padrões distribuídos em nível local e poderão subsidiar, em trabalhos futuros, a formulação de medidas propositivas que visem o suporte à tomada de decisão, por parte do gestor público, de forma a minimizar eventuais distorções na distribuição e no provimento da mobilidade e da acessibilidade metropolitanas.

\section{3- MATERIAL E MÉTODOS}

O objetivo do trabalho, como estabelecido inicialmente, é verificar em que medida a acessibilidade potencial interfere na mobilidade efetiva das pessoas, considerando o transporte público por ônibus. Para tanto, foram desenvolvidos três indicadores de acessibilidade e três indicadores de mobilidade, que resultaram, respectivamente, em um Índice de Acessibilidade Potencial (IAP) e um Índice de Mobilidade Efetiva (IME). Os indicadores e índices podem servir para um conjunto de aplicações de acordo com os objetivos em estudo. Dentre as aplicações, destacam-se as seguintes: atribuição de recursos, classificação de locais, cumprimento de normas, análise de tendências, informação ao público e investigação científica (AGÊENCIA PORTUGUESA DO MEIO AMBIENTE, 2000; GUDMUNDSSON, 2004; BRACARENSE, 2014). Os indicadores são obtidos a partir de um conjunto de dados e podem gerar índices, que representam uma medida única, cujos valores servem como ferramentas de auxílio a tomadas de decisão e de análise de situações atuais e futuras (AGÊNCIA PORTUGUESA DO MEIO AMBIENTE, 2000; SAISANA et al., 2015). Para a construção dos indicadores e índices foi utilizada uma base dados secundários, provenientes de entidades de pesquisa e desenvolvimento como:

Cadernos do Leste

Artigos Cientificos

Belo Horizonte, Jan.-Dez. Vol.16, n¹6, 2016 
a) Agência de Desenvolvimento da Região Metropolitana: base de dados digital da Pesquisa Origem/Destino (OD) de 2012 (MINAS GERAIS, 2012);

b) BHTRANS (Empresa de Transportes e Trânsito de Belo Horizonte): base de dados digital dos pontos, itinerários e o quadro de horários das linhas de ônibus do município (BELO HORIZONTE, 2011a);

c) IBGE (Instituto Brasileiro de Geografia e Estatística): base de dados digital do Censo Demográfico 2010 (BRASIL, 2010b);

d) PRODABEL (Empresa de Informática e Informação do Município de Belo Horizonte): base de dados digital das Regionais ${ }^{1}$ e Sub-Regionais; Áreas de Proteção Ambiental; lagos e lagoas do município (BELO HORIZONTE, 2011b; 2012; 2016).

Como dito anteriormente, neste artigo, em função dos propósitos estabelecidos inicialmente, optou-se em analisar os indicadores e índices a partir das unidades espaciais denominadas campos, que compreendem agregações de áreas homogêneas ${ }^{2}$ (Figura 1). Trata-se de unidades espaciais de vida urbana, caracterizadas como áreas de coletas adequadas para se estabelecer amostras mínimas das condições sociais e econômicas locais (MINAS GERAIS, 2003). Ressalta-se que todos os campos estudados foram considerados como representantes potenciais equivalentes de atividades, dessa forma, a densidade de oportunidades foi desconsiderada.

A pesquisa origem-destino é uma designação genérica de uma pesquisa decenal cujo objetivo principal é a produção de informações básicas necessárias para o planejamento e gestão do transporte e do tráfego metropolitanos. Ela fornece um retrato dos principais padrões de deslocamento das pessoas na RMBH, correspondentes a um dia útil típico (MINAS GERAIS, 2003). Ainda, segundo Minas Gerais (2012), os resultados da Pesquisa OD 2012 constituem

\footnotetext{
1 “As Regiões Administrativas de Belo Horizonte são subdivisões gerenciais do Município sendo elas: Barreiro, CentroSul, Leste, Nordeste, Noroeste, Norte, Oeste, Pampulha e Venda Nova. Essa divisão atende à necessidade por descentralização e coordenação de programas e atividades adequados às particularidades de cada região da cidade." (BELO HORIZONTE, 2017).

2 Menor nível de desagregação espacial, utilizado nas Pesquisas OD da Região Metropolitana de Belo Horizonte $(\mathrm{RMBH})$.
}

Cadernos do Leste

Artigos Cientificos

Belo Horizonte, Jan.-Dez. Vol.16, n¹6, 2016 
relevante ferramenta para o Sistema de Planejamento e Gestão Metropolitano, servindo de subsídios para outros instrumentos, tais como detalhamentos do Plano Diretor de Desenvolvimento Integrado, que define macrodiretrizes para políticas públicas na região, e programas de governo como o Pacto Metropolitano pela Sustentabilidade, o Projeto Estruturador RMBH e principalmente o Plano de Mobilidade da RMBH.

Figura 1: Regionais e campos do município de Belo Horizonte
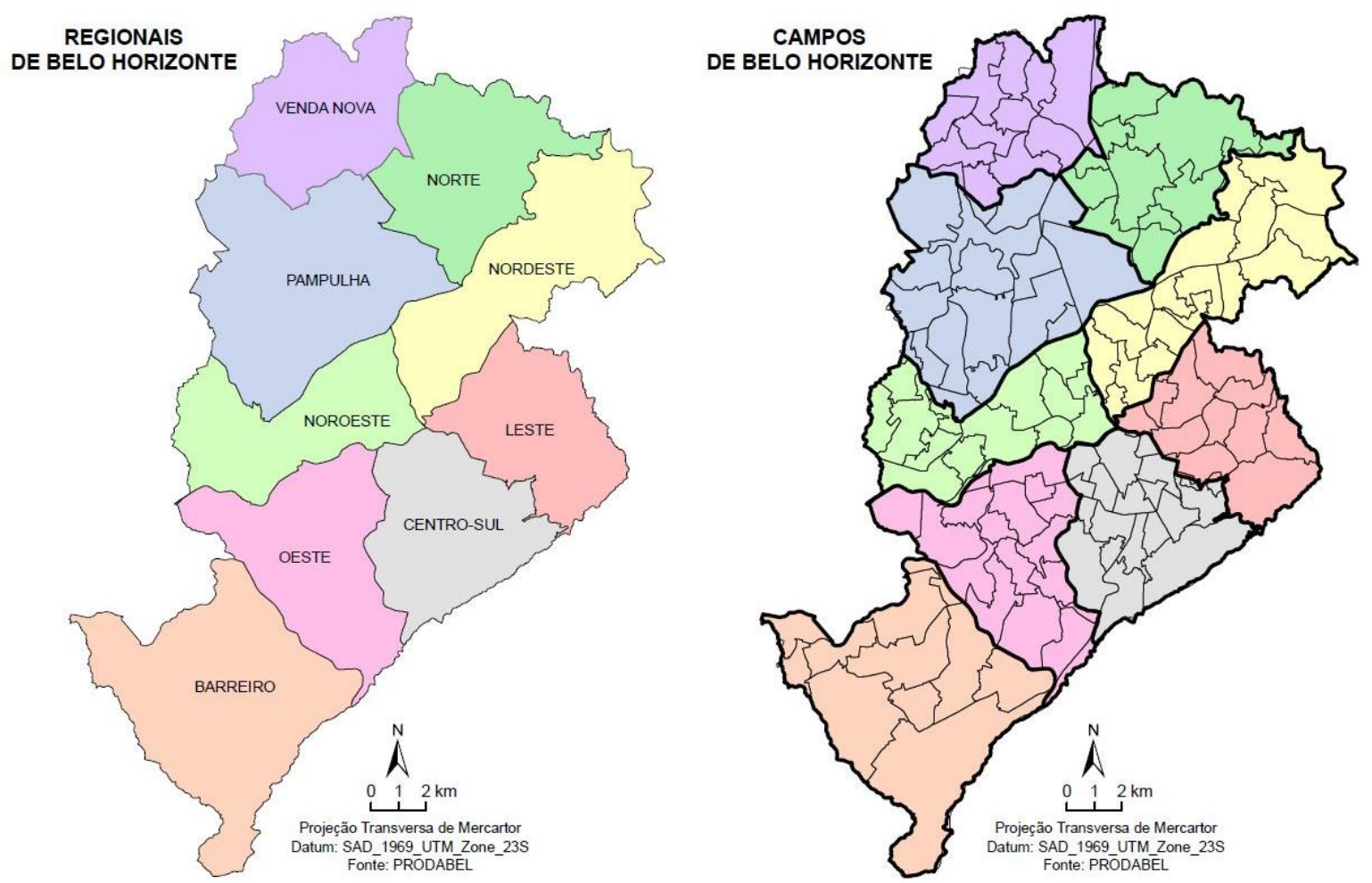

Fonte: Elaboração própria. Base de dados Belo Horizonte (2011b; 2012).

A análise espacial foi realizada a partir do modelo Geographically Weighted Regression (GWR), que verificou, de forma isolada, a predição do IME (variável dependente), com base no IAP (variável independente/explicativa). O GWR é uma ferramenta desenvolvida com o propósito de analisar fenômenos que sofrem variação na área estudada, derivada da heterogeneidade espacial. O modelo GWR tem como base o ajustamento de um modelo de regressão local para cada elemento no conjunto de dados, ponderando as observações em razão da distância a esse elemento. Pressupõe-se que os pontos mais próximos ao ponto de estudo têm maiores influências nos Cadernos do Leste Artigos Cientificos Belo Horizonte, Jan.-Dez. Vol.16, n¹6, 2016 
parâmetros da regressão que os mais distanciados (CARVALHO et al., 2006). O método utilizado para definir a largura de banda ou vizinhos foi o AICc, uma medida de desempenho e útil para comparar diferentes modelos de regressão (LOBO et al., 2015) e, de forma complementar, o Kernel como método de classificação, que leva em conta a distância de cada elemento amostral, cujo centroide corresponde ao ponto mais próximo do verto de valores observados para o respectivo elemento (MINGOTI, 2005). Além dos índices de regressão local (Local R2) estimados para cada campo, foram identificados os padrões e a distribuição espacial dos resíduos (escores de resíduo padronizado), que representam os casos de menor e maior explicação do modelo.

\section{a. Índice de Acessibilidade Potencial (IAP)}

O IAP tem como finalidade medir a acessibilidade potencial da população ao sistema de transporte público por ônibus. Esse índice foi construído a partir da média aritmética dos três indicadores descritos nas subseções a seguir.

i. Indicador Razão de Densidade (IRD)

Segundo dados da BHTRANS (BELO HORIZONTE, 2015), o município de Belo Horizonte tem, ao todo, 9.343 pontos de ônibus distribuídos em 120 campos. A correspondência pontos por campo foi realizada no ArcGIS. O IRD tem por objetivo estabelecer a relação (padronizada) entre o número de pontos em cada campo $\left(\mathrm{N}_{\mathrm{c}}\right)$ e as respectivas densidades demográficas $\left(\mathrm{DD}_{\mathrm{c}}\right)$, como apresentado na Equação 1:

$$
R D_{c}=\frac{N_{c}}{D D_{c}}
$$

Em que: $R D_{c}$ é a razão de densidade de cada campo; $D D_{c}=\frac{P O P_{c}}{A_{c}}$; e $A_{c}$, a área do campo em $\mathrm{km}^{2}$. A fim de evitar viés nas estimativas dos índices, para o cálculo da densidade demográfica $\left(D D_{c}\right)$ das unidades territoriais estudadas, as áreas de proteção ambiental (ZPAM) e de lagoas foram desconsideradas.

Cadernos do Leste

Artigos Cientificos

Belo Horizonte, Jan.-Dez. Vol.16, n¹6, 2016 
Encontradas as $R D_{c}$, foi realizada a padronização de seus valores (IRD), em uma escala de 0 (mínimo de densidade de pontos por densidade demográfica) a 1 (máximo de densidade de pontos por densidade demográfica), a partir da Equação 2:

$$
I R D=\frac{R D_{c_{i}}-R D_{c_{\text {min }}}}{R D_{c_{\text {máx }}}-R D_{c_{\text {min }}}}
$$

ii. Indicador Razão de Linhas (IRL)

Esse indicador tem por objetivo definir o número médio de linhas que passam nos pontos de cada campo. Para tanto, foi encontrada a $R L_{c}$ (Equação 3).

$$
R L_{c}=\frac{\sum L_{c}}{N_{c}}
$$

Em que: $R L_{c}$ é a razão de linhas de cada campo; $L_{c}$, o número de linhas que passa em cada ponto de um determinado campo, e $N_{c}$ número de pontos em cada campo. O IRL é a normalização dos valores de $R L_{c}$ calculados, utilizando a mesma lógica da Equação 2.

iii. Indicador Razão de Frequência (IRF)

O IRF tem por objetivo definir a frequência média das linhas nos pontos de cada campo. Para tanto, foi encontrada a $R F_{c}$ (Equação 4).

$$
R F_{c}=\frac{\sum F_{c}}{N_{c}}
$$

Em que: $R F_{c}$ é a razão de frequência de cada campo; $F_{c}$, a frequência das linhas que passam em cada ponto de um determinado campo, e $N_{c}$ número de pontos em cada campo. O IRF é a normalização dos valores de $R F_{c}$ calculados, utilizando a mesma lógica da Equação 2.

Cadernos do Leste

Artigos Cientificos

Belo Horizonte, Jan.-Dez. Vol.16, n¹6, 2016 


\section{b. Índice de Mobilidade Efetiva (IME)}

O IME tem como finalidade medir a facilidade efetiva de deslocamento diário, por ônibus, da população no município de Belo Horizonte.

i. Indicador Razão de Mobilidade (IRM)

O IRM tem por objetivo definir a proporção entre o número de viagens que partem de um determinado campo e a sua população. Para tanto, foi encontrado a $R M_{c}$ (Equação 5).

$$
R M_{c}=\frac{N v_{c}}{P O P_{c}}
$$

Em que: $R M_{c}$ é a razão de mobilidade de cada campo; $N v_{c}$, o número de viagens que partem de um determinado campo; e $P O P_{c}$, a população do campo.

O número de viagens que parte de um determinado campo $\left(N v_{c}\right)$ foi retirado da Pesquisa OD 2012 (MINAS GERAIS, 2012), já com a aplicação dos fatores de expansão determinados pela própria pesquisa (ANEXO 1). Ainda, como o objetivo é avaliar a mobilidade por ônibus da população de cada campo, foram desconsideras as viagens em áreas de passagem (onde ocorrem as baldeações, por exemplo). Assim, apenas as viagens com a origem "residência" ("motivo origem") e o destino "não residência" ("motivo destino”), realizadas pelo modo ônibus, foram utilizadas na análise. O IRM é a normalização dos valores de $R M_{C}$ calculados, utilizando a mesma lógica da Equação 2.

ii. Indicador Razão de Conectividade (IRC):

O IRC tem por objetivo analisar a capacidade de um campo qualquer se conectar aos outros campos, por meio do sistema de transporte coletivo por ônibus. Para tanto, foi encontrado a $R C_{c}$ (Equação 6).

Cadernos do Leste

Artigos Cientificos

Belo Horizonte, Jan.-Dez. Vol.16, n¹6, 2016 


$$
R C_{c}=\frac{N d_{c}}{(N d-1)}
$$

Em que: $R C_{c}$ é a razão de conectividade de cada campo; $N d_{c}$, o número de destinos possíveis, a partir de um determinado campo, utilizando o modo ônibus; e $N d$, o número de campos do município de Belo Horizonte $(N d=120)$. O número de destinos possíveis, a partir de um determinado campo, utilizando o modo ônibus $\left(N d_{c}\right)$, foi retirado da Pesquisa OD 2012 (MINAS GERAIS, 2012), com os mesmos filtros descritos na subseção anterior. O IRM é a normalização dos valores de $R M_{c}$ calculados, utilizando a mesma lógica da Equação 2.

iii. Indicador Eficiência de Mobilidade (IEM):

O IEM tem por objetivo comparar a eficiência das viagens por ônibus entre as unidades espaciais analisadas. Foi utilizada como variável de análise a velocidade, calculada a partir da distância euclidiana entre os centroides $\left(D_{\text {centroides }}\right)$ dos campos e dos tempos de deslocamento declarados na OD 2012 ( $\left.t_{\text {declarados }}\right)$. No cálculo das velocidades dos deslocamentos dentro da mesma unidade espacial, a distância considerada foi o raio de um círculo com área igual à do campo. A eficiência de mobilidade $\left(E M_{C}\right)$ é dada pela média das velocidades calculadas das viagens realizadas entre os pares de campos de origem/destino $\left(N v_{c}\right)$, conforme indicado na Equação 7. O IEM é a normalização dos valores de $E M_{c}$ calculados, utilizando a mesma lógica da Equação 2.

$$
E M_{c}=\frac{\sum \frac{D_{\text {centroides }}}{t_{\text {declarados }}}}{N v_{c}}
$$

Nota-se que a velocidade utilizada não é a real, os valores calculados são subdimensionados, visto que foram consideradas as menores distâncias entre dois pontos do terreno, desprezando as variações topográficas e, sobretudo, o trajeto real dos ônibus. Assim sendo, a velocidade calculada é apenas uma (boa) proxy, que permite comparar a eficiência nas viagens entre as unidades espaciais analisadas.

Cadernos do Leste

Artigos Cientificos

Belo Horizonte, Jan.-Dez. Vol.16, n¹6, 2016 


\section{4- RESULTADOS}

Os cartogramas da Figura 2 apresentam os indicadores que compõem o IAP. Os indicadores de razão de densidade e de frequência (IRD e IRF, respectivamente) não apresentam uma tendência bem definida, tendo, dessa forma, uma distribuição aleatória no espaço. O Indicador Razão de Linhas (IRL) apresentou uma tendência um pouco mais clara na região pericentral do município, onde os valores são mais altos, o que é esperado, considerando a configuração radioconcêntrica do sistema viário da cidade e, em consequência, do sistema de transporte por ônibus. Porém, no restante dos campos, a distribuição do IRL também é aleatória. É interessante observar que os campos que apresentaram IRL com valores de médio a alto, seguem a linha de Trem Metropolitano (metrô de superfície) do município (ANEXO 2). A limitada capilaridade espacial do metrô (que se resume a uma única linha) exige a existência de "complementação" do transporte para atendimento às diversas áreas da cidade. Nesse sentido, embora não haja uma grande integração física e tarifária dos sistemas metrô e ônibus em Belo Horizonte, os sistemas atuam de forma relativamente integrada, de forma a ampliar o alcance espacial dos serviços. Porém, os três indicadores revelaram, em sua maioria, valores muito baixos (de 0,0 a 0,2$)$, resultando em baixos IAP em grande parte do território.

O IAP evidencia diferenças importantes, no que diz respeito à acessibilidade ao modo de transporte por ônibus dos campos do município de Belo Horizonte, como apresenta a Figura 3. A região pericentral, assim como as regionais Pampulha, Norte e Nordestes são as porções que apresentam o maior potencial de acessibilidade a partir do modo coletivo por ônibus. É interessante observar que os campos que apresentaram maiores IAP, ou têm em seu território uma estação de integração BHBus³; ou são campos vizinhos a essas estações; ou são bordeados por corredores viários importantes e com grande densidade de pontos de ônibus, como é o caso do campo Calafate e o seu entorno, bordeados pela Avenida Pedro II e Via Expressa. No sentido inverso, os extremos das porções noroeste, leste e oeste do município são os que apresentam maior problema de

\footnotetext{
${ }^{3}$ Estações de Integração entre linhas do transporte coletivo.
}

Cadernos do Leste

Artigos Cientificos

Belo Horizonte, Jan.-Dez. Vol.16, n¹6, 2016 
acessibilidade por ônibus, indicando onde são necessários investimentos em acesso ao modo coletivo no município. Nessas regiões está localizada a maioria dos campos que possuem um IPA abaixo de 0,15 .

O Índice de Mobilidade Efetiva revela diferenças importantes, no que diz respeito aos deslocamentos por ônibus dos campos do município de Belo Horizonte, como apresenta a Figura 5. As regiões periféricas apresentam o maior número de deslocamentos por ônibus. Ao contrário do Índice de Acessibilidade Potencial, as regionais Venda Nova, Noroeste e Leste apontam maior IME, indicando que, apesar da população se deslocar de forma expressiva utilizando o sistema de ônibus (alta demanda), existe uma grande dificuldade de acesso ao modo nessas porções. Isso reforça, mais uma vez a necessidade de investimentos em transporte público coletivo nas regiões indicadas. Ainda, é notória a influência dos grandes eixos no IME, por exemplo, a BR-040 exerce grande influência no índice de mobilidade na região sul do município. A região norte sofre interferência de um número maior de grandes vias (principalmente da BR-381, MG-020, Avenida Antônio Carlos, Avenida Cristiano Machado, Avenida Dom Pedro I e da MG-10).

Cadernos do Leste 
Figura 2: Indicador Razão de Densidade (IRD), Indicador Razão de Linhas (IRL), Indicador Razão de Frequência (IRF) do município de Belo Horizonte/MG 

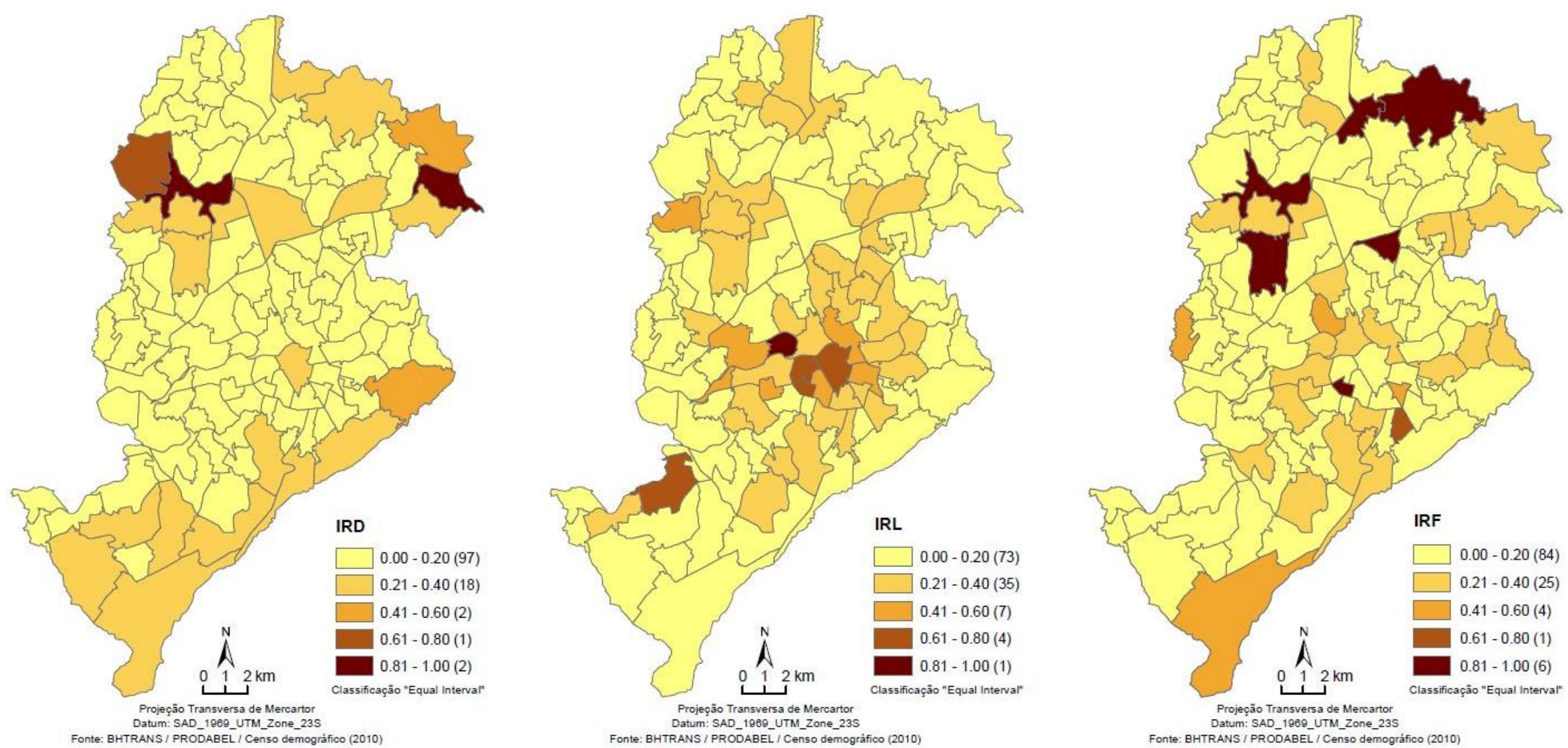

Fonte: Elaboração própria. Base de dados digital Belo Horizonte (2012; 2015; 2016)a e Brasil (2010b).

Cadernos do Leste

Artigos Cientificos
Belo Horizonte, Jan.-Dez. Vol.16, n¹6, 2016 
Figura 3: Índice de Acessibilidade Potencial (IAP) do município de Belo Horizonte

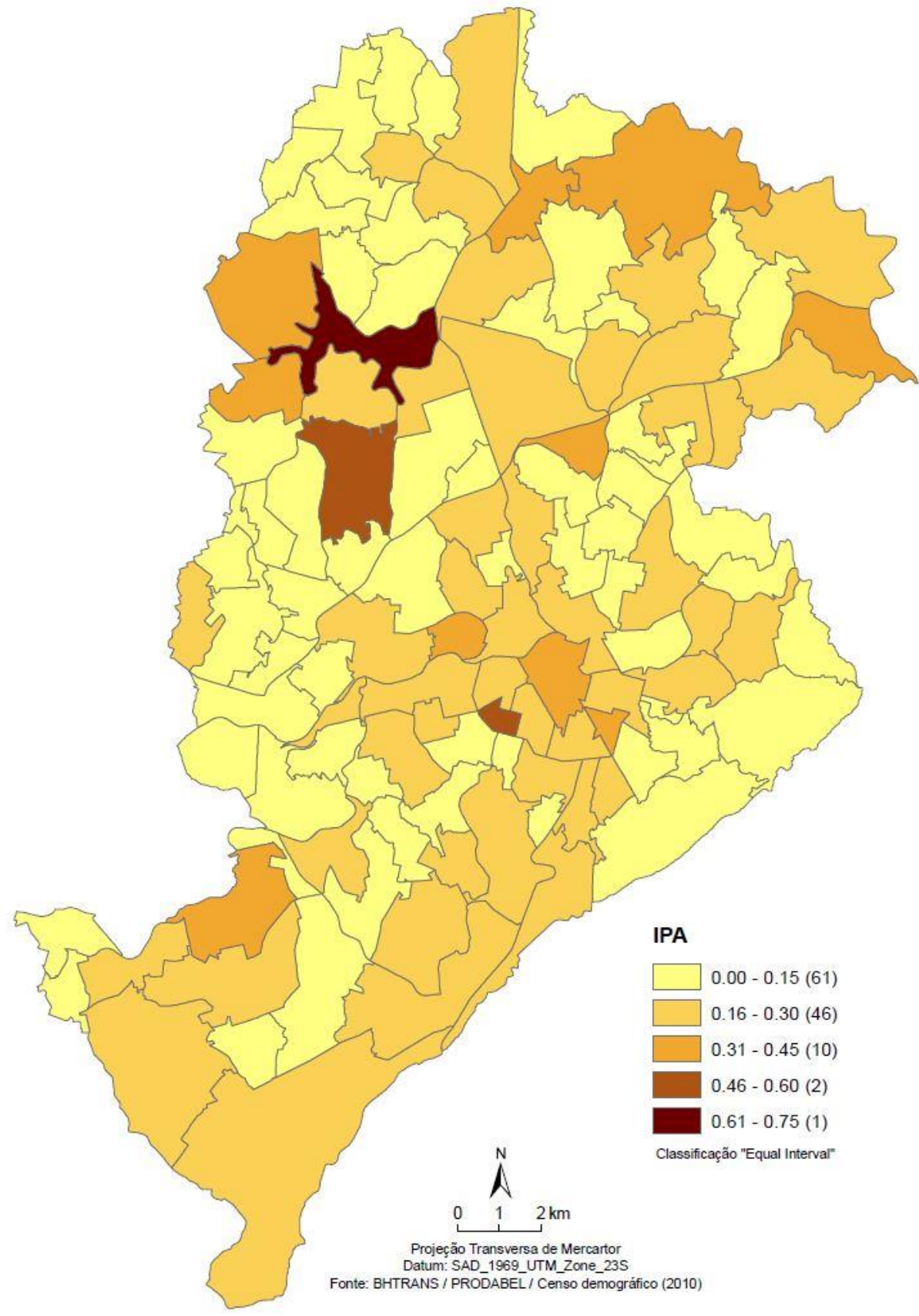

Fonte: Elaboração própria. Base de dados digital Minas Gerais (2012), Belo Horizonte (2012) e Brasil (2010b).

Cadernos do Leste Artigos Cientificos 
Figura 4: Indicador Razão de Mobilidade (IRM), Indicador Razão de Conectividade (IRC), Indicador Eficiência de Mobilidade (IEM) do município de Belo Horizonte/MG 

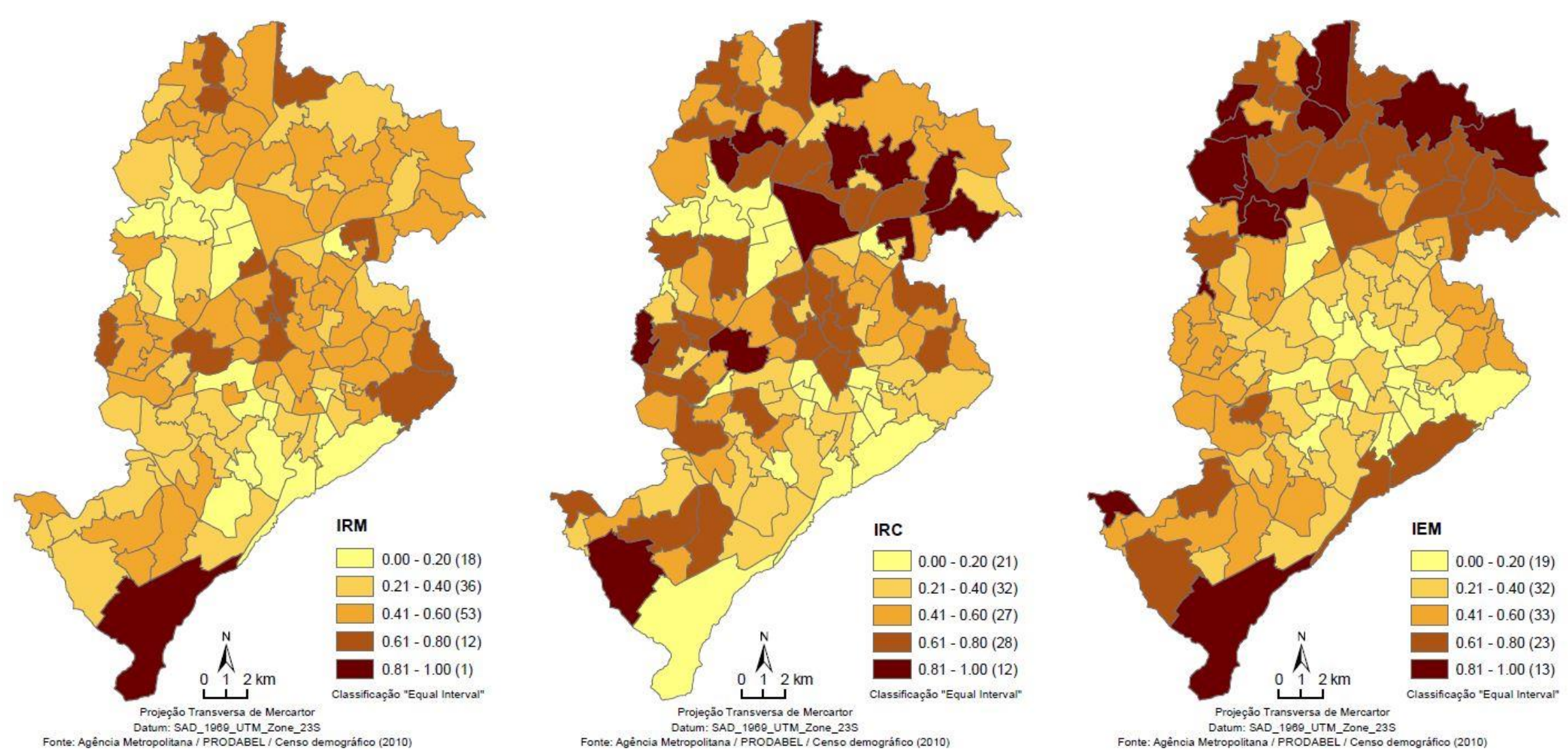

Fonte: Elaboração própria. Base de dados digital Minas Gerais (2012), Belo Horizonte (2012) e Brasil (2010b). 
Figura 5: Índice de Mobilidade Efetiva (IME) do município de Belo Horizonte

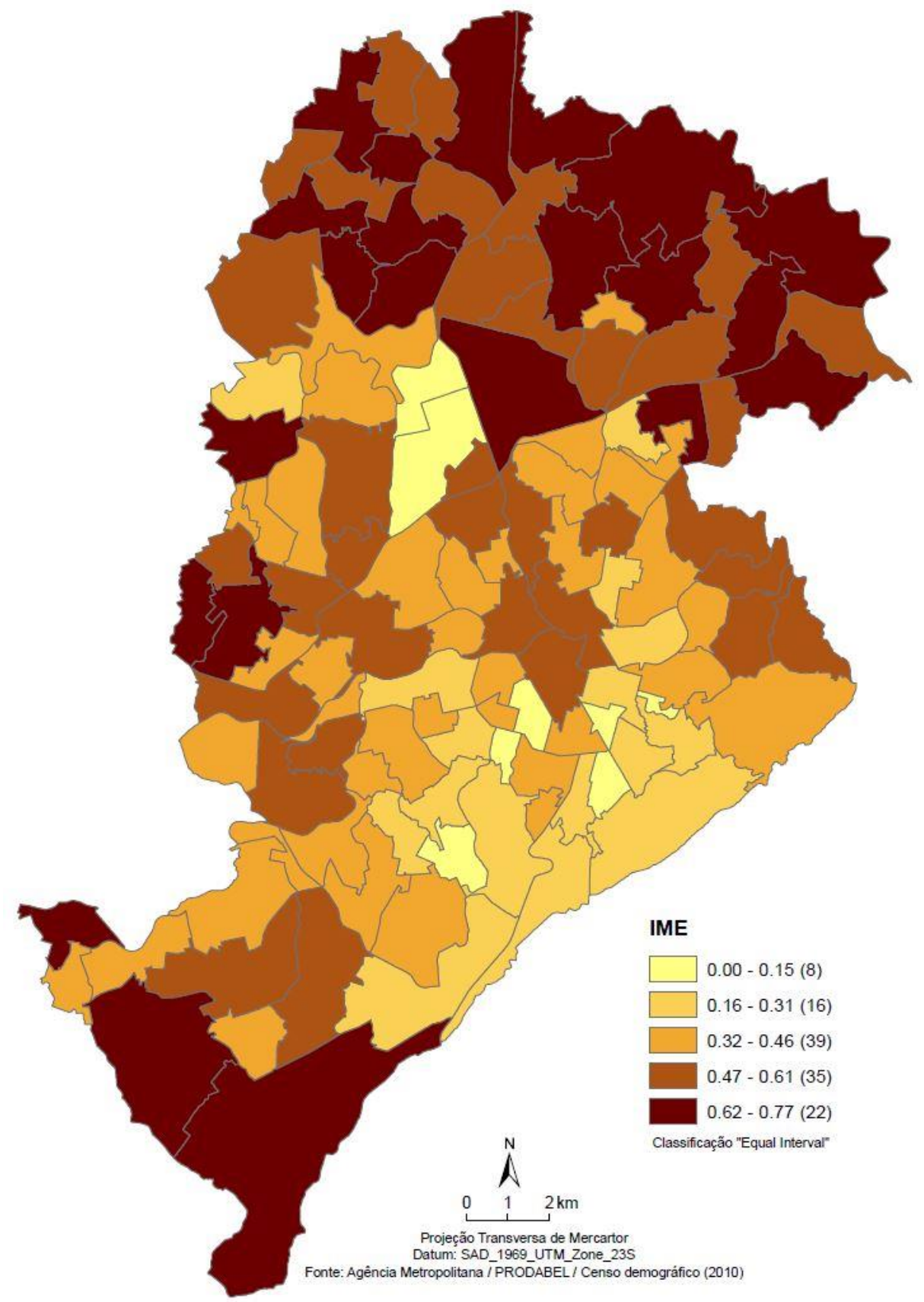

Fonte: Elaboração própria. Base de dados digital Minas Gerais (2012), Belo Horizonte (2012) e Brasil (2010b).

A Figura 6 apresenta a (não) correlação entre as variáveis IPA (independente) e IME (dependente). A análise global dessas duas variáveis, realizada a partir do modelo de regressão linear, indica que acessibilidade potencial ao transporte coletivo por ônibus não reflete em uma Cadernos do Leste Artigos Cientificos Belo Horizonte, Jan.-Dez. Vol.16, n¹6, 2016 
maior mobilidade da população de Belo Horizonte. O fator de predição do modelo não é representativo $\left(R^{2}=7 \times 10^{-7}\right)$, sendo, dessa forma, necessária(s) outra(s) variável(is) para a explicação do IME.

Figura 6: Regressão linear entre IPA e IME de Belo Horizonte

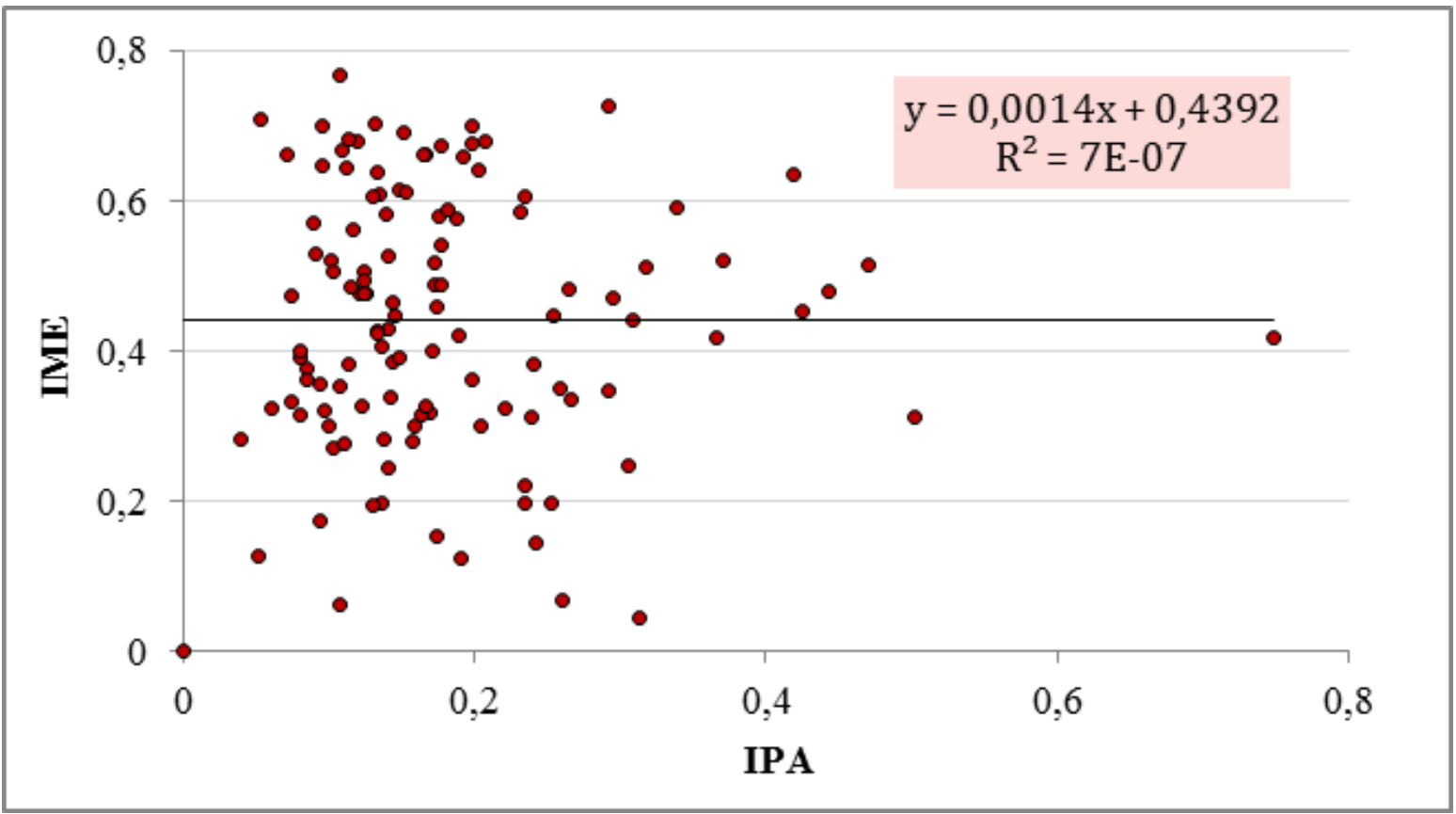

Fonte: Elaboração própria.

A análise local das variáveis, realizada a partir do modelo GWR (Figura 7), não indica a associação direta entre a variável dependente (IME) e a variável explicativa (IAP). Assim, não é verificada, a partir dos índices construídos neste artigo, a interferência da potencialidade de acesso ao transporte público por ônibus, na facilidade do deslocamento diário das pessoas.

Os escores de $R^{2}$ local, apesar de permitirem identificar algumas particularidades da distribuição espacial, também foram muito baixos (a maioria não ultrapassa o valor de 0,15), o que também sugere a baixa correlação entre os dois índices. Da mesma forma, os escores de resíduo padronizado apresentaram uma distribuição aleatória, não indicando, assim, uma tendência bem definida na relação entre as duas variáveis. Ainda, observando o cartograma de resíduo padronizado (Figura 7) é possível concluir que nas regiões mais periféricas (menos abastadas) a maior parte da população utiliza o modo coletivo por ônibus em seus deslocamentos, apesar da baixa acessibilidade (Resíduo Padronizado positivo). Nas regiões mais abastadas, o Resíduo Padronizado Cadernos do Leste Artigos Cientificos 
é negativo, indicando que mesmo existindo o fácil acesso ao sistema de transporte coletivo por ônibus, a população utiliza outros modos de transporte (geralmente o individual motorizado), como é o caso do campo "Santo Antônio - São Pedro", com o escore de Resíduo Padronizado de $-1,67$.

Figura 7: Regressão Espacialmente Ponderada (GWR): R² e Resíduos Padronizados
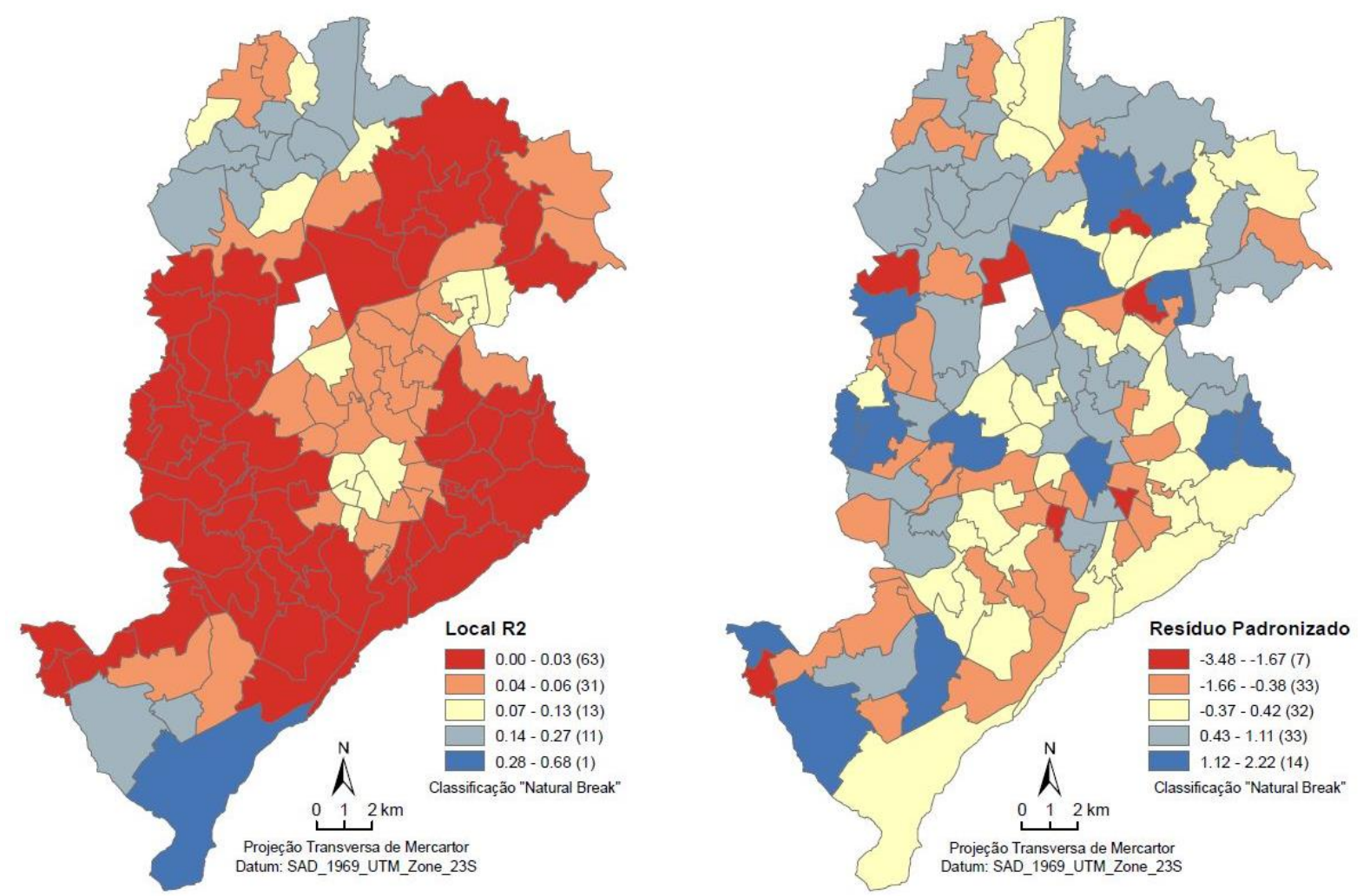

Fonte: Elaboração própria. Base de dados digital de Minas Gerais (2012), Belo Horizonte (2012; 2015; 2016) e Brasil (2010b).

Desse modo, como afirmado anteriormente, a análise de regressão geograficamente ponderada comprovou uma das afirmações de Handy (2002): uma boa acessibilidade não é condição suficiente e nem necessária para uma boa mobilidade. Assim sendo, o fato de existirem menores obstáculos ao deslocamento, não significa, necessariamente, maior mobilidade por ônibus. Além da disponibilidade de serviços de transporte, outras variáveis também podem influenciar na relação, como por exemplo, as dimensões do espaço urbano, a complexidade das

Cadernos do Leste Artigos Cientificos Belo Horizonte, Jan.-Dez. Vol.16, n¹6, 2016 
atividades nele desenvolvidas, bem como as características da população (renda, faixa etária e renda), que refletem em suas necessidades.

\section{5- CONSIDERAÇÕES FINAIS}

Os conceitos de acessibilidade e mobilidade têm sido amplamente utilizados na literatura, sob as mais diversas abordagens e aplicações, principalmente de forma isolada. Assim, a contribuição que este trabalho pretende oferecer está fundamentada em dois aspectos: a) a construção de novos indicadores e índices de acessibilidade e mobilidade, e b) a investigação da relação dos dois conceitos, a partir de uma análise GWR, realizada com o apoio de um Sistema de Informação Geográfica (SIG), de fundamental importância em grande parte das etapas desenvolvidas neste estudo. A facilidade na edição e visualização gráfica desse sistema torna o processo, de análise e tomada de decisão, mais transparente e rápido.

O estudo teve como objetivo é verificar em que medida a acessibilidade potencial interfere na mobilidade efetiva das pessoas, considerando o transporte público por ônibus. Para tanto, foram desenvolvidos três indicadores de acessibilidade potencial e três indicadores de mobilidade efetiva, que resultaram, respectivamente, em um Índice de Acessibilidade Potencial (IAP) e um Índice de Mobilidade Efetiva (IME). A análise espacial foi realizada a partir do modelo Geographically Weighted Regression (GWR) e não apontou influência direta da acessibilidade potencial na mobilidade efetiva das pessoas. Assim, foi constatado que o potencial de utilização de modo de transporte não permite, necessariamente, que destinos desejados possam ser atingidos por aqueles modos, uma vez que a mobilidade também pode estar associada às características próprias do indivíduo, relacionadas às condições física e econômica e às suas necessidades; ou mesmo às dimensões do espaço urbano e a complexidade das atividades nele desenvolvida.

Dessa forma, os resultados obtidos do confronto do Índice de Acessibilidade Potencial com o Índice de Mobilidade Efetiva permitem o reconhecimento de padrões distribuídos em nível local e poderão subsidiar, em trabalhos futuros, a formulação de medidas propositivas que visem o suporte à tomada de opinião e de decisão, de forma a minimizar eventuais distorções na distribuição e no provimento da mobilidade e da acessibilidade urbanas e metropolitanas, 
contribuindo, assim, para a adequação da circulação viária e, consequentemente, para o melhor aproveitamento das oportunidades de "consumo" do espaço urbano. 


\section{REFERÊNCIAS BIBLIOGRÁFICAS}

AGÊNCIA PORTUGUESA DO MEIO AMBIENTE. Proposta para um sistema de indicadores de desenvolvimento sustentável. Amadora, Portugal, 2000. 228p. (Relatório)

AGUILAR, C. C.; MARTINS, R.; FIGUEIREDO, L.; LEMOS, M. B. Indicador de Acessibilidade para Análise do Desenvolvimento Regional. Revista Econômica do Nordeste, v. 41, p. 581-598, 2010.

ALMEIDA, A. Hidrovia Tocantins-Araguaia: importância e impactos econômicos, sociais e ambientais segundo a percepção dos agentes locais. 2004. Tese (Doutorado em Ciências) - Escola Superior de Agricultura Luiz de Queiroz, Universidade de São Paulo, Piracicaba, 2004.

BARROS, A. R.; RAPOSO, I. Dotação de infraestrutura como limitante para redução de disparidades regionais no Brasil. In: ENCONTRO NACIONAL DA ASSOCIAÇÃO BRASILEIRA DE ESTUDOS REGIONAIS, 15., 2002, São Paulo. Anais... São Paulo: ENABER, 2002.

BELO HORIZONTE. BHTRANS. Empresa de Transportes e Trânsito de Belo Horizonte. Prefeitura de Belo Horizonte. 2015. Disponível em: <http://www.bhtrans.pbh.gov.br /portal/page/portal/portalpublico>. Acesso em: 15 março 2015.

BELO HORIZONTE. BHTRANS. Plano de Mobilidade Urbana de Belo Horizontes (PlanMob-BH). Empresa de Transportes e Trânsito de Belo Horizonte. Prefeitura de Belo Horizonte, 2010. (Relatório final).

BELO HORIZONTE. BHTRANS. Rede de transporte público coletivo de Belo Horizonte. Empresa de Transportes e Trânsito de Belo Horizonte. Prefeitura de Belo Horizonte. 2011a. Disponível em: <http://www.bhtrans.pbh.gov.br/portal/pls/portal/!PO RTAL.wwpob_page.show?_docname=4722216.PDF>. Acesso em: 15 janeiro 2017.

BELO HORIZONTE. PRODABEL. Base digital das áreas de proteção ambiental; lagos e lagoas. Empresa de Informática e Informação do Município de Belo Horizonte. Prefeitura de Belo Horizonte. 2016.

BELO HORIZONTE. PRODABEL. Base digital das regiões administrativas Belo Horizonte - 2011. Empresa de Informática e Informação do Município de Belo Horizonte. Prefeitura de Belo Horizonte. 2011b.

BELO HORIZONTE. PRODABEL. Base digital de sub-regiões 2013-2014. Empresa de Informática e Informação do Município de Belo Horizonte. Prefeitura de Belo Horizonte. 2012.

BELO HORIZONTE. SECRETARIA MUNICIPAL ADJUNTA DE GESTÃO COMPARTILHADA. Regiões Administrativas. 2017. Disponível em: < http://gestaocompartilhada.pbh.gov.br/estrutura-territorial/regioes-administrativas $>$. Acesso em: 20 jan. 2017.

Cadernos do Leste

Artigos Científicos

Belo Horizonte, Jan.-Dez. Vol.16, n¹6, 2016 
BIGOLIN, E. M.; GOLDNER, L. G.; ULYSSÉA NETO, I. Análise da concentração espacial e estudo de mobilidade por transporte coletivo, através do uso de um sistema de informações geográficas. In: CONGRESO LATINOAMERICANO DE TRANSPORTE PÚBLICO Y URBANO, 15., 2009, Buenos Aires. Anais... Buenos Aires: CLATPU, 2009.

BRACARENSE, L. S F. P dos; FERREIRA, J. O. N. Índice proposto para comparação de acessibilidade dos modos de transporte privado e coletivo. In: CONGRESSO DE ENSINO E PESQUISA EM TRANSPORTES, 28., 2014, Curitiba. Anais... Curitiba: ANPET, 2014.

BRASIL. DENATRAN. Relatórios estatísticos: frota de veículos por município 2000. Departamento Nacional de Trânsito. Ministério das Cidades. 2000. Disponível em: <http://www.denatran.gov.br/index.php/estatistica/237-frota-veiculos>. Acesso em: 15 janeiro 2017.

BRASIL. DENATRAN. Relatórios estatísticos: frota de veículos por município 2010. Departamento Nacional de Trânsito. Ministério das Cidades. 2010a. Disponível em: <http://www.denatran.gov.br/index.php/estatistica/237-frota-veiculos>. Acesso em: 15 janeiro 2017.

BRASIL. DENATRAN. Relatórios estatísticos: frota de veículos por município 2016. Departamento Nacional de Trânsito. Ministério das Cidades. 2016. Disponível em: <http://www.denatran.gov.br/index.php/estatistica/237-frota-veiculos>. Acesso em: 15 janeiro 2017.

BRASIL. IBGE. Censo demográfico 2010. Instituto Brasileiro de Geografia e Estatística. 2010b. Disponível em: <http://censo2010.ibge.gov.br>. Acesso em: 17 abril 2016.

BRASIL. Ministério das Cidades. Secretaria Nacional de Transporte e Mobilidade Urbana. Política Nacional de Mobilidade Urbana Sustentável. Brasília, 2004.

BRASIL. Política Nacional de Mobilidade Urbana. Lei no 12.587, de 3 de janeiro de 2012. Diário Oficial da União, Poder Legislativo, Brasília, DF, 4 jan. 2012. Seção 1, p. 1.

CAMPOS, V. B. G.; RAMOS, R. A. R. Proposta de indicadores de mobilidade urbana sustentável relacionando transporte e uso do solo. In: CONGRESSO LUSO-BRASILEIRO PARA O PLANEJAMENTO URBANO, REGIONAL, INTEGRADO E SUSTENTÁVEL 1., 2005, São Carlos. Anais... São Carlos, Brasil: PLURIS, 2005.

CARDOSO, L. Transporte público, acessibilidade urbana e desigualdades socioespaciais na região metropolitana de Belo Horizonte. 2007. Tese (Doutorado em Geografia) Universidade Federal de Minas Gerais, Belo Horizonte, 2007.

CARDOSO, L.; LOBO, C. F. F. Mobilidade espacial da população na Região Metropolitana de Belo Horizonte: análises da acessibilidade com base no censo demográfico de 2010. Revista dos Transportes Públicos, v. 135, n. 1, p. 21-40, 2013.

Cadernos do Leste

Artigos Cientificos

Belo Horizonte, Jan.-Dez. Vol.16, n¹6, 2016 
CARVALHO, L. E.; SILVA, H. N.; LOUREIRO, C. F. G.; MENSESES, H. B. Regressão Linear Geograficamente Ponderada em ambiente SIG. Transportes, v. XIV, n. 2, p. 18-26, 2006.

DINIZ, C. C. Capitalismo, recursos naturais e espaço. 1987. Tese (Doutorado em Economia) - Instituto de Economia, Universidade Estadual de Campinas, Campinas, 1987.

GONZAGA, A. S. S. da; KNEIB, E. C. A investigação da acessibilidade em municípios conurbados: o caso da região metropolitana de Goiânia. In: CONGRESSO DE ENSINO E PESQUISA EM TRANSPORTES, 30., 2016, Rio de Janeiro. Anais... Rio de Janeiro: ANPET, 2014. p. 2609-2944.

GUDMUNDSSON, H. Sustainable Transport and Performance Indicators, In: HESTER, R. E.; HARRISON, R. M. (Eds.) Transport and the environment. Cambridge: Issues in environmental science and technology (20), Royal Society of Chemistry, 2004. p. 35-63.

HANDY, S. Accessibility - vs. Mobility - enhancing strategies for addressing automobile dependence in the U.S. In: EUROPEAN CONFERENCE OF MINISTERS OF TRANSPORT, 2002, Paris. Research Report... Paris: ECMT, 2002.

HANSEN, W. G. Accessibility and residential growth.1959. Dissertação (Mestrado em Planejamento Urbano) - Massachusetts Institute of Technology, Massachusetts, 1959.

JONES, S. R. Accessibility measures: a literature review. Transport and Road Research Laboratory, Laboratory Report 967, 1981.

KOENIG, J. G. Indicators of urban accessibility: theory and application. Transportation, v. 9, n.2, p. $145-172,1980$.

LIMA, J. H.; OLIVEIRA, M. A, de; MAIA, M. L. A. Como medir a variação de acessibilidade causada pela implantação de um território gerador de viagens?. Revista Transportes, v. 24, n. 2, 2016.

LOBO, C. F. F.; CARDOSO, L. e MATOS, R. Transporte coletivo em Belo Horizonte: a eficiência de acessibilidade com base na Pesquisa Domiciliar Origem e Destino de 2002. In: CONGRESSO LUSO-BRASILEIRO PARA O PLANEJAMENTO URBANO, REGIONAL, INTEGRADO E SUSTENTÁVEL 4., 2010, Faro. Anais... Faro, Portugal: PLURIS, 2010.

LOBO, C. F. F.; CARDOSO, L. e MATOS, R. Transporte coletivo em Belo Horizonte: a eficiência de acessibilidade com base na Pesquisa Domiciliar Origem e Destino de 2002. Revista dos Transportes Públicos, v. 130, n. 1, p. 101-113, 2012.

LOBO, C. F. F.; CARDOSO, L.; MAGALHÃES D. J. A. V. Acessibilidade e mobilidade espaciais da população na Região Metropolitana de Belo Horizonte: análise com base no censo demográfico de 2010. Caderno Metropolitano, São Paulo, v. 15, n. 30, p. 513-533, 2013.

Cadernos do Leste

Artigos Cientificos

Belo Horizonte, Jan.-Dez. Vol.16, n¹6, 2016 
LOBO, C.; FONSECA, D. F.; GARCIA, R. A. Verticalização e permeabilização do solo urbano nos setores censitários de Belo Horizonte/MG. Revista Brasileira de Estudos Urbanos Regionais, v. 17, n.13, p. 215-228, 2015.

MAKRI, M. C.; FOLKESSON, C. Accessibility measures for analyses of land use and travelling with geographical information systems. In: KFB - RESEARCH CONFERENCE 2., 1999, Lund, Sweden. Proceedings... Lund, Sweden: KFB, p.1-17, 1999.

MINAS GERAIS. Pesquisa Origem e Destino 2001 - 2002. Fundação João Pinheiro, 2003. (Relatório consolidado).

MINAS GERAIS. Pesquisa Origem e Destino 2011 - 2012. Agência de Desenvolvimento da Região Metropolitana de Belo Horizonte, 2012. (Relatório).

MINGOTI, S. A. Análise de dados através de métodos de estatística multivariada: uma abordagem aplicada. Belo Horizonte: Ed. UFMG, 2005.

MORRIS, J. M.; DUMBLE, P. L.; WIGAN, M. R. Accessibility indicators for transport planning. In: AUSTRALIAN TRANSPORT RESEARCH FORUM, 4., 1978, Perth. Forum Papers... Perth: ATRF, Office of the Director General of Transport, 1978, v. 1, p. 41-73.

OECD. Road Safety Annual Repport. International Traffic Safety Data and Analysis Group (IRTAD). Disponível em: < <ttp://www.itf-oecd.org/road-safety-annual-report-2013>. Acesso em: 14 janeiro 2016. (Report).

OLIVEIRA, G. M de; RODRIGUES DA SILVA, A. N. Desafios e perspectivas para avaliação e melhoria da mobilidade urbana sustentável: um estudo comparativo de municípios brasileiros. Transportes, v. 23, n. 1, p. 59-68, 2015.

RAIA JR., A. A. Acessibilidade e mobilidade na estimativa de um índice de potencial de viagens utilizando redes neurais artificiais e sistemas de informação. 2000. Tese (Doutorado em Engenharia Civil Transportes) - Escola de Engenharia de São Carlos, Universidade de São Paulo, São Carlos, 2000.

RIGOLON, F. J. Z.; PICCININI, M. S. Investimento em infraestrutura e a retomada do crescimento econômico. Rio de Janeiro: BNDES, 1997. (Texto para Discussão, 63).

SAISANA, M.; TARANTOLA, S.; SCHULZE, N.; CHERCHYE, L;. MOESEN, W. E PUYENBROECK, T. V. Knowledge economy indicators: state of the art report on composite indicators for the knowledge-based economy. Ispra, Italia: JRC, European Commission Joint Research Centre, 2005. 64p.

SATHISAN, S. K.; SRINIVASAN, N. Evaluation of accessibility of urban transportation networks. Transportation Research Record, n. 1617, p. 78-83,1998.

Cadernos do Leste

Artigos Cientificos

Belo Horizonte, Jan.-Dez. Vol.16, n¹6, 2016 
TAGORE, M. R.; SIKDAR, P. K. A new accessibility measure accounting mobility parameters. In: WORLD CONFERENCE ON TRANSPORT RESEARCH, 7., 1995, Sydney, Australia. Proceedings... The University of New South Wales, Sydney, Australia: WCTR, 1995.

ULYSSÉA NETO, I.; SILVA, B. R. Um método de análise de mobilidade por transporte coletivo urbano: desenvolvimento e aplicação à cidade de Florianópolis - SC. In: CONGRESSO DE PESQUISA E ENSINO EM TRANSPORTES, 18., 2004, Florianópolis. Anais... Florianópolis: ANPET, 2004.

VASCONCELLOS, E. A. Transporte urbano, espaço e equidade: Análise das políticas públicas. $2^{a}$ ed. São Paulo: Annablume, 2001.

VERAS, D. F. G.; PINTO, G. F. N.; LOBO, C. F. F.; CARDOSO, L.; GARCIA, R. A. Acessibilidade urbana em Belo Horizonte: apontamentos sobre a acessibilidade aos serviços de transporte coletivo municipal. In: CONGRESSO LUSO-BRASILEIRO PARA O PLANEJAMENTO URBANO, REGIONAL, INTEGRADO E SUSTENTÁVEL 7., 2016, Maceió. Anais... Maceió, Brasil: PLURIS, 2016. 


\section{ANEXO 1}

\section{DISTRIBUIÇÃO GEOGRÁFICA DO FATOR DE EXPANSÃO}

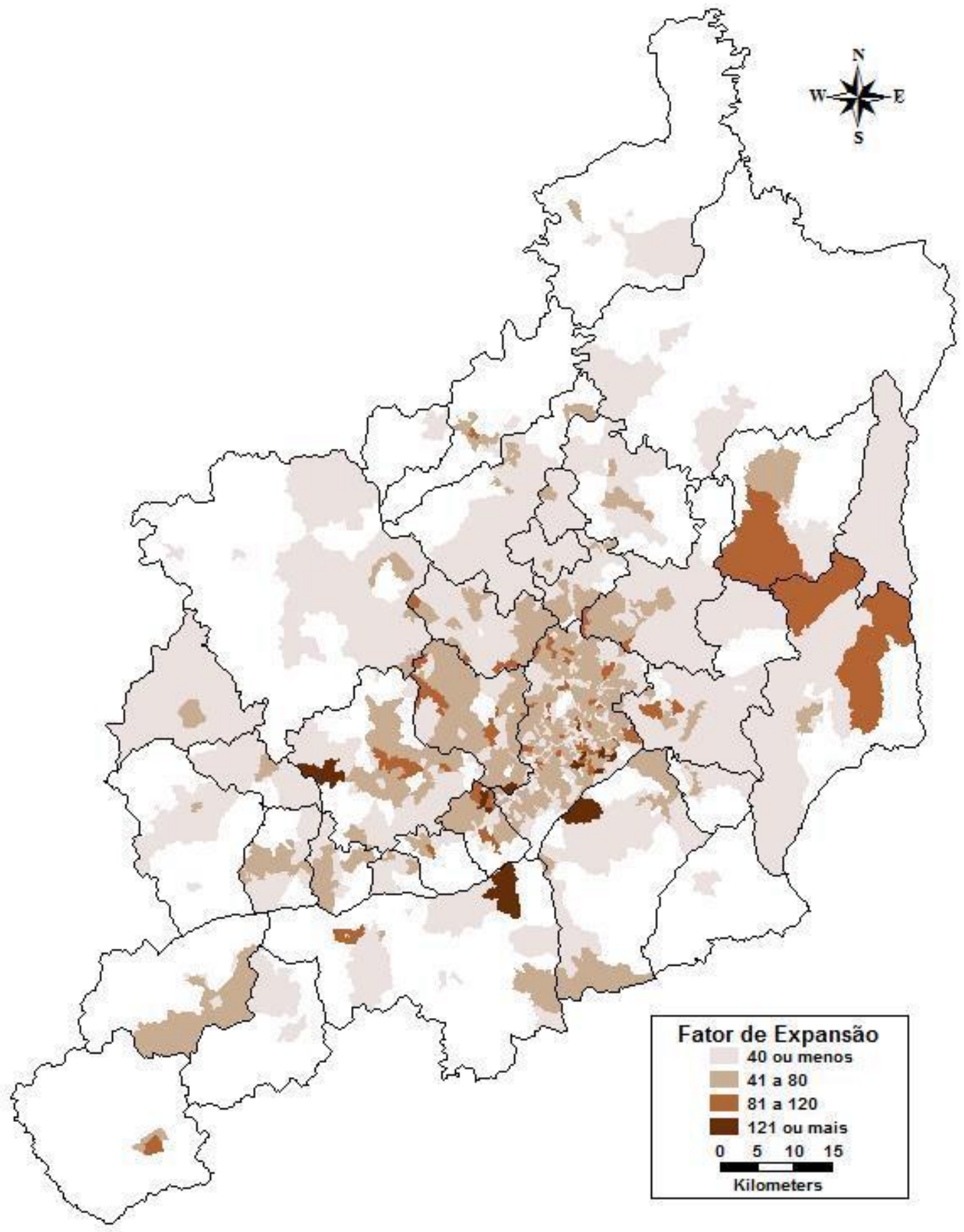

Fonte: Minas Gerais (2012).

Cadernos do Leste Artigos Cientificos
Belo Horizonte, Jan.-Dez. Vol.16, n¹6, 2016 
ANEXO 2

MAPA REDE DE TRANSPORTE COLETIVO BH

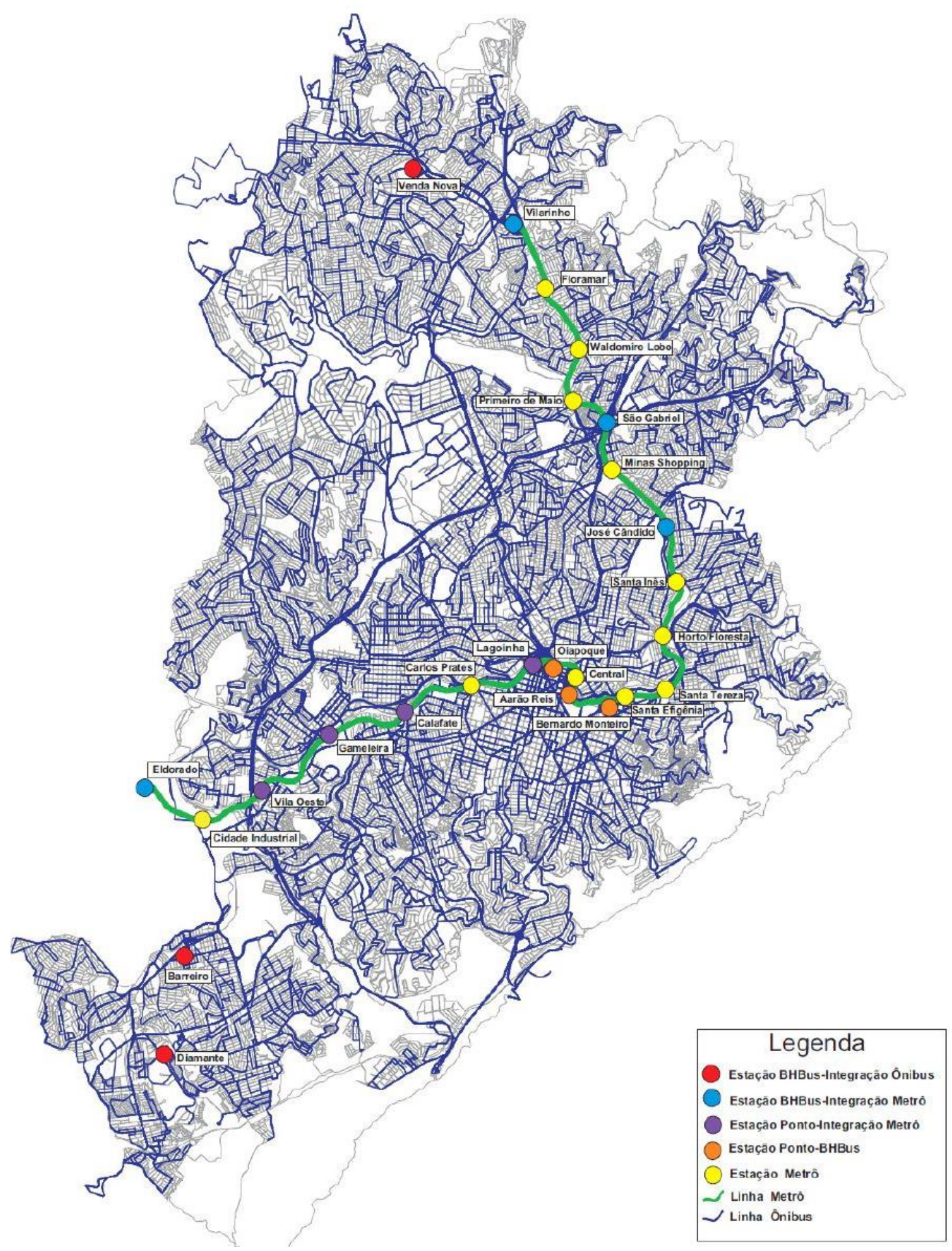

Fonte: Belo Horizonte (2011a).

Cadernos do Leste

Artigos Científicos

Belo Horizonte, Jan.-Dez. Vol.16, n¹6, 2016 